Copyright C1997, American Institute of Aeronautics and Astronautics, Inc.

AIAA Meeting Papers on Disc, January 1997

A9715748, AIAA Paper 97-0734

\title{
University of Michigan's Aerospace Engineering Curriculum 2000
}

\author{
K. Powell \\ Michigan Univ., Ann Arbor \\ M. Parsons \\ Michigan Univ., Ann Arbor \\ V. Coppola \\ Michigan Univ., Ann Arbor \\ J. Eisley \\ Michigan Univ., Ann Arbor \\ D. Hyland \\ Michigan Univ., Ann Arbor \\ A. Messiter \\ Michigan Univ., Ann Arbor \\ A. Waas \\ Michigan Univ., Ann Arbor \\ B. Cosgrove \\ Michigan Univ., Ann Arbor
}

\begin{abstract}
AIAA, Aerospace Sciences Meeting \& Exhibit, 35th, Reno, NV, Jan. 6-9, 1997
This paper summarizes a two-part curriculum reform that is well under way in the University of Michigan Aerospace Engineering Department. The first part of the reform was developed by a college-wide task force, and addressed the overall structure of the 13 Bachelor's of Science in Engineering (BSE) programs across the college, and the courses that are common to all of the engineering curricula. The second part of the reform was developed inside the Aerospace Engineering Department, and addressed the portion of the curriculum unique to aerospace, as well as how the Aerospace Department chose to implement the recommendations of the college-wide effort. The primary elements of the reform include the adoption of a four-credit per course/four course per semester/eight semesters to graduation $(4 \times 4 \times 8)$ model, and one engineering course each semester of the freshman year (the first an introduction to engineering, the second an introduction to computers and computing), and enhanced flexibility for students to tailor their senior years to address specific career goals. (Author)
\end{abstract}




\title{
University of Michigan's Aerospace Engineering Curriculum $2000^{1}$
}

\author{
K. Powell ${ }^{2}$, M. Parsons ${ }^{3}$, V. Coppola ${ }^{2}$, J. Eisley ${ }^{2}$, D. Hyland ${ }^{2}$, \\ A. Messiter ${ }^{2}$, A. Waas ${ }^{2}$ and B. Cosgrove
}

\begin{abstract}
This paper summarizes a two-part curriculum reform that is well underway in the University of Michigan Aerospace Engineering Department. The first part of the reform was developed by a college-wide task force, and addressed the overall structure of the thirteen Bachelor's of Science in Engineering (BSE) programs across the College, and the courses that are common to all of the engineering curricula. The second part of the reform was developed inside the Aerospace Engineering department, and addressed the portion of the curriculum unique to Aerospace, as well as how the Aerospace department chose to implement the recommendations of the college-wide effort. The primary elements of the reform are:

- The adoption of a four-credit per course/four course per semester/eight semesters to graduation $(4 \times 4 \times 8)$ model.

- One engineering course each semester of the freshman year - the first an introduction to enginecring; the second an introduction to computers and computing.

- Enhanced flexibility for students to tailor their senior years to address specific career goals.

- The implementation of implicit curricular "threads" (i.e. coverage of topics via coordinated portions of courses throughout the four-year program, as opposed to coverage in a separate course).

- written, oral and visual technical communications;

- engineering problem solving through computing;

- engineering ethics;

- teamwork and team leadership;

- randomness and uncertainty;

- environmental impacts and issues.
\end{abstract}

- Increased use of teamwork in courses: five of the ten required courses inside the Aerospace department are to be based on team projects and team grades.

- A two-semester seminar sequence, covering current topics in aerospace and case studies in engineering.

- A two-semester design sequence.

Development of the outlines and supporting materials, including educational software modules, for new and modified courses is now underway. First-year students entering in Fall 1997, the graduating class of 2001, will go through the new curriculum.

\footnotetext{
${ }^{1}$ An on-line version of this paper can be accessed on the Aerospace Department home page [1]

Aerospace Fugineering Department

${ }^{3}$ Associate Deas for Undergraduate Programs

"Visiting Faculty Member, Supported by the Boeing Fellow-on-Campus Program
} 


\section{The College-Wide Curriculum 2000 Effort}

\subsection{Introduction}

In summer of 1995, an Undergraduate Curriculum Task Force was formed and charged with the following mission:

Design the core undergraduate curriculum and the model for the overall College of Engineering undergraduate curriculum into which the departments will be able to fit their individual program curricula, paying particular attention to the skills and knowledge which will characterize the Michigan Bachelor of Science in Engineering experience.

The make-up of the task force was quite broad: it was chaired by the Associate Dean for indergraduate Education, and had representatives from each of the ten departments, the graduate and undergraduate student bodies, alumni, the College's Executive Committee, and the College's Curriculum Committee. The first author, who was chair of the College's Curriculum Committee at the time, represented the Curriculum Committee and the Aerospace Department on the Task Force; the second author was the Associate Dean for Undergraduate Education at the time. Liaisons from the Math, Physics, Chemistry, Biology and English departments also worked with the Task Force.

The work of the Task Force was influenced by a substantial amount of reference material, including reports on engineering education by the American Society of Engineering Education [2], the Accreditation Board for Engineering and Technology [3], and the National Research Council [4].

The recommendations of the Task Force were reached through a consensus decision process. The recommendations were the focus of the Spring 1996 meeting of the College of Engineering National Advisory Committee, composed of leaders of business and industry. The National Advisory Committee strongly endorsed the proposed changes and recommended that, the College faculty adopt the recommendations for all programs as soon as practicable. The faculty voted to adopt the recommendations in Spring 1996, and departments began working on how to implement revised curricula that met the guidelines spelled out in the Task Force recommendations.

\subsection{Recommendations of the Task Force}

After two semesters of work, the Undergraduate Curriculum Task Force proposed for facilty approval:

1. a. mission statement and education goals for the College's undergraduate programs; and

2. a list of 21 specific recommendations, touching on nearly every aspect of the undergraduate curriculum.

\subsubsection{Mission Statement and Educational Goals}

The mission statement and education goals approved by the faculty are presented below. 
Mission: The mission of the undergraduate degree programs of the University of Michigan College of Engineering is to prepare our graduales to begin a lifetime of technica! and professional creativity and leadership in their chosen fields.

Educational Goals: The College of Engineering will provide our students with a wide choice of degree programs of the highest quality. These degree programs will be accredited by the Accreditation Board for Engineering and Technology where this is consistent with the professional objectives of the degree program. Recognizing that our undergraduale students have many different career objectives, the College will provide and support three distinct educational opportunities:

- For students who qualify and wish to enter the practice of their engineering profession with the highest entry-level technical preparation, the College will provide simultaneous BSE/MSE and BSE/Master of Engineering (MEng) paths that can generally be completed in 10 semesters without significant advanced placement credit.

- For students who uish to enter engineering practice with only entry-level preparation or who wish to pursue professional graduate work in alternative ficlds such as business, law, or medicine, the College will provide BSE and BS paths that can generally be complete in 8 semesters without significant advanced placement credit.

- For students who qualify and wish to pursue advanced graduate study within engineering in preparation for careers in engineering research and education, the College will provide a Research Honors BSE path characterized by significant research experience during the final $\stackrel{\text { years. }}{\square}$

Students will be admitted directly to the College of Engineering and will pursue a common first year. The College and its programs will not ask students to make their choice of major either formally or de facto prior to the end of the first year.

These statements are significant in that they formally commit the College to a goal of graduation in eight semesters and acknowledge for the first time that not all our BSE students are preparing to be traditional practicing engineers. They also move toward the five-year M.S.F. as the preferred/recommended entry level for our top engineering graduates. They recommit to a long Michigan tradition of giving our incoming students a year to explore their interests before choosing an engineering major.

\subsubsection{Summary of Specific Recommendations}

A high-level summary of the more sweeping of the 21 recommendations approved by the faculty is given below.

Adoption of a $4 \times 4 \times 8$ Model One of the primary issues the Task Force addressed in its work was the time to graduation. Data taken by the College showed that, clespite the fact that many students enter with a substantial number of advanced placement credits, the time to graduate with a Bachelor's degree had crept up over the years, so that the average time to graduate was 4.7 years. While many causes contribute to this effect, the consensus of the 
committec was that two of the causes were paramount, and able to be addressed through curriculum reform:

1. Students were being required to take between five and six courses a term to graduate;

2. Many of these courses, through "curriculum creep," had become packed with material to such an extent that this five-to-six course load was untenable for the average student.

Besides the time-to-graduate issue, the Task Force was cognizant of the fact that adoption of a $4 \times 4 \times 8$ model also had a "clean slate" effect, forcing each department to re-think its entire curriculum, rather than tweaking the current one.

Freedom of Choice Michigan Enginecring students have a wide range of talents, interests and career goals. They also have exceptional opportunities to use their talents, explore their interests, and prepare themselves for their career goals, since they are in a university that is one of the best and most comprehensive in the world, with top-ranked business, law, medicine, and literature/science/arts schools. For students to be able to take advantage of this, however, there has to be freedom in their curricula. The Task Force proposed that a minimum of 12 credits of unrestricted electives and 12 credits of technical electives (in addition to the 16 credits of required humanities/social sciences) was a necessary part of each department's curriculum.

Freshman Courses The Task Forcc proposed that two freshman courses in the College of Engineering be required. The first is an introductory course entitled "Engineering 100 - Introduction to Engineering." Each lecture section will comprise roughly 80 students, and will be taught by a team led by an Engineering professor assisted by one member of the Technical Communications staff and two graduate-student instructors. The course will feature integrated learning in three areas:

- project-based work in the Engineering professor's discipline, undertaken by student tearns;

- training in the written, oral and visual communication skills demanded of engineering; and

- training in team building and teamwork.

In the process of introducing and supporting the project, the course would also inchide covcrage of

- the role of the engineer in society; and

- ethical, environmental and quality issues concerns in the engineering profession.

The second is a course entitled "Engineering 101 - Introduction to Computers and Computing." "This course will cover:

- software issues 
- programming concepts and programming

- algorithms

- realizing algorithms as programs

- structuring data and control in programs

- hardware issues

- computer structure

- computer operation

- clata, memory, execution

- the spectrum of instruction - from circuit logic to high-level languages.

Issues Covered Across the Curriculum Neither of the courses outlined above is expected to culminate a student's study of the subject, but rather to lay the foundation for Curther work throughout a student's program. The Task Force recommended that communications instruction, experiences and feedback, roughly equivalent to one full course's worth, are to be implemented in later required courses for each department. Engineering problem solving using the computer was recommended for similar treatment. In addition, engineering ethics, environmental impacts and issues, and randomness/uncertainty were recommended to be treated similarly.

Assessment A variety of assessment mechanisms were recommended to be put in place, including improved course evaluations and regular alumni surveys.

\subsection{A Funny Thing Happened on the Way to a Quorum}

In spite of the number and variety of recommendations in the Task Force's proposal to the faculty, and the substantial impact most of the recommendations would have on faculty and students, discussion focused, almost from the start, on the $4 \times 4 \times 8$ recommendation. This recommendation tumed out to be the "hot-button issue" of curriculum reform. Faculty approval across the College was sought for the mission and educational goals and then separately for the entire package of 21 recommendations in a two-issue mail ballot. The two votes were favorable by five-to-one and two-to-one margins, respectively. The final report of the Task Force was distributed to faculty and students, and made avaialable on the World Wide Web [5].

\section{The Aerospace Engineering Curriculum 2000 Effort}

\subsection{Introduction}

During the time that the Undergraduate Curriculum Task Force was doing its work, the Aerospace Department was hiring a new chairman, contemplating a strategic-planning exercise, and beginning a curriculum revision effort of its own. This confluence of events led to ar excellent environment for a clean-slate approach to the Aerospace undergraduate curriculim. 
Out of the department's stratcgic planning effort, the following mission statement was dratted. In addition, a number of strategic goals and objectives were developed: the ones most relevant to the undergraduate curriculum in the department are listed below. The departmental mission statement and the strategic goals and objectives (available on the World Wide Web [1]), in addition to the work of the College's Undergraduate Curriculum Task Force, gave the Aero Curriculum 2000 a framework on which to build.

\subsubsection{Department of Aerospace Engineering Mission}

As the first aeronautics program in the nation, and the program with the largest number of atrospace engineering alumni, our Mission is to provide internationally recognized leadership in aerospace engineering education and research by being a place that ...

- Recognizes that aerospace engineering comprises disciplines and technologies that are distinct in the manner of their integration and application and must be taught accordingly.

- Educales students who are widely known for exceptional strength in technical fundamentals across all aerospace disciplines, who are cognizant of modern aerospace technologies, and who are sought after by top graduale schools and by aerospace and relaied industries worldwide.

- Offers a varicty of cxccllent degree programs satisfying the needs of a diverse body of students, with graduates that are of exceptionally high and lifelong value to aerospace and related industries worldwide.

- Supports vibrant and highly recognized research programs that serve the educational goals of its undergraduate and graduate degree programs, that make major contributions to the knowledge base in aerospace sciences and technology, and that are turned to by industry and government for solutions.

- Creates an environment of unsurpassed intellectual challenge and excitement that at the same time is collegial and conducive to higher learning.

- Takcs full advantage of the unparalleled breadth of knowledge, technology, facilities, and resources of the first aeronautics program nationwide at one of the largest and most highly regarded universities worldwide, The University of Michigan.

\subsubsection{Strategic Goal - Undergraduate Education}

Provide a continuously improving educational program that graduates students with strong engineering science fundamentals while incorporating applied engineering aspects. The education program should

- allow students to meet their career goals.

- attract outside employers and graduate schools to Michigan graduates.

- continue to improve and build on the Aerospace Department's reputation of producing excellent engineers. 


\subsubsection{List of Strategic Objectives}

1. Increase flexibility for students to choose a varied career path.

2. Require breadth of knowledge across aerospace engineering disciplines.

3. Ensure balance between engineering practice and engineering science.

4. Integrate current software and laboratory technolgy into courses.

5. Introduce synthesis/systems/design perspective at an early level and reinforce it throigh later work.

The "Aero Curriculum 2000" committee was charged with designing a framework for a new undergraduate curriculum for the department that helped the department accomplish its mission by addressing the goals and objectives listed above. While the college-wide Curriculum 2000 initiative instigated the formation of the committee, the opportunity was used to design a curriculum that addresses issues raised by alumni surveys, industry feedback, the departmental review, and faculty discussions. Besides the inputs mentioned above, the current curricula at MIT, GA Tech, Maryland, Ohio State and Purdue were studied, and contrasted to Michigan's current program in the design of the new one.

\subsection{The New Aerospace BSE Program}

\subsubsection{Objectives to be met by the new framework}

Based on input from the various sources mentioned above, the committee tried to achieve the following goals in the new curriculum framework.

- Maintain enough "basic engineering" in the curriculum that students have the breadth necessary to operate in the current work environment.

- Define a baseline number of required courses, leaving students more freedom to tailor their senior years to address their specific career goals.

- Maintain a balance of "engincering science" and "engineering" courses in the curriculum.

- Strengthen the design portion of the undergraduate experience.

- Add more of a vehicle/systems flavor to the core discipline courses.

- Organize the CAD/CAM/CAE elements of the courses so that students can use software to solve progressively more complex problems as they approach graduation.

- Integrate the use of analysis software in the curriculum so as to decrease the current emphasis on hand calculation and to enable students to solve more sophisticated problems.

- Mect the criteria sct in the Collcge's Curriculum 2000 guidelines. 


\subsubsection{Synopsis of the Structure of the new curriculum}

The new Aero curriculum has the following structure:

- Three extra-departmental introductory courses

- Five engineering science courses, introducing the disciplines of aerospace engineering.

- Five engineering courses (a vehicle performance course, two lab courses, and two design courses).

- Two required one-credit seminar courses.

- Three technical elective courses, one of which qualifies as an advanced math or science elective.

In the engineering courses, all homework/projects/grades will be team-based. For some projects, small teams (three or four students) will be formed. For others, particularly the upper-level design courses, larger teams will be formed. In some courses, students will be in several different teams over the course of the semester; in others they will be in the srine team for the whole course.

Technical electives will be classified in the following categories:

- Advanced math;

- Advanced science;

- Advanced aerospace sciences;

- Advanced engineering;

- Engineering in context (law, management, economics, business).

Advising plans, based on students' career plans, will suggest from which categories students should choose their technical electives. Each student will (as is currently the case) be assigned an Aerospace faculty member as his or her advisor.

\subsubsection{Detailed Structure of the New Curriculum}

Curriculum Framework The overall curriculum framework is given in the following table. The department teaching each upper-level course is listed in parentheses.

Courses in Literature, Science and the Arts

$\begin{array}{ll}\text { Humanities/Social Sciences } & 4 \text { courses } \\ \text { Mathematics } & 4 \\ \text { Physics } & 2 \\ \text { Chemistry/Biology } & 1\end{array}$


Enginecring Freshman Courses

Engin 100 - Tech Comm/Engin Intro 1 course

Engin 101 - Computing and Computers 1

Introductory Courses

Electrical Engineering I (EE) 1 course

Matcrials/Strength of Materials (Materials) 1

Introduction to Dynamics (Mechanical) 1

Discipline Courses

Thermo and Gas Dynamics (Aero) 1 course

Aircraft and Spacecraft Propulsion(Aero) 1

Airplane Aerodynamics (Aero) 1

Aircraft and Spacecraft Structures (Aero) 1

Stability \& Control of Flight (Aero) 1

Engineering Courses

Performance of Aircraft \& Spacecraft (Aero) 1 course

Lab courses (Aero) 2

Intro to Design with CAD (Aero) 1

Advanced Design (Aero) 1

Seminar Courses

Current Issues in Aerospace Industry (Aero) 1 one-credit course

Case Studies in Engineering (Aero) 1 one-credit course

Electives

Advanced math/science clective 1 course

Technical electives 2

Free Electives 3

A sample schedule for this curriculum

First term Second term Third term Fourth term

$\begin{array}{llll}\text { Math I } & \text { Math II } & \text { Math III } & \text { Math IV } \\ \text { Engin 100 } & \text { Phys I } & \text { Phys II } & \text { Materials/Strength } \\ \text { Chemistry } & \text { Fng 101 } & \text { Performance } & \text { Thermodynamics } \\ \text { H/SS } & \text { H/SS } & \text { Dynamics } & \text { H/SS }\end{array}$

Fifth term Sixth term Seventh term Eighth term

$\begin{array}{llll}\text { Structures } & \text { Aerodynamics } & \text { Tab II } & \text { Design II } \\ \text { Propulsion } & \text { Design I } & \text { Tech Elec } & \text { Tech Elec } \\ \text { Electrical Eng I } & \text { Lab I } & \text { Tech Elec } & \text { Free Elec } \\ \text { H/SS } & \text { Stability \& Control } & \text { Free Elec } & \text { Free Elec } \\ \text { Seminar I } & \text { Seminar II } & & \end{array}$


A note on the upper-level design courses One of the major objectives of this new curriculum framework is to introduce software tools and aircraft/spacecraft component design at the sophomore and junior levels. This allow the upper-level design courses to focus on advanced design of a vehicle or complex component. Because students will have experience with analysis software and with working in teams, they should be able to accomplish somewhat more in these courses than in the past.

In addition to the technical content specific to the course topic (i.e. aircraft or space system design), the following will be a part of each of these courses:

- Team projects (with team grading and peer evaluation) and concurrent engineering;

- Continued development of communication skills;

- Economic considerations and customer requirements;

- Discussion of manufacturability, maintainability and product life cycle;

- Benchmarking techniques for comparing similar designs;

- Legal, ethical and environmental aspects.

\section{Implementation of "Threads" in the new curriculum}

Written. oral and visual communication

Engineering 100 will give the students substantial training and experience in communications. In addition, there will be technical writing and speaking elements in the laboratory and design courses, and in the performance course (which would be the students" first, course in the department). Technical communications staff will be involved in adding these elements to these courses (or upgrading what we have already done in them), and with grading of written and oral presentations.

Engineering problem solving through computing

The freshman/sophomore mathematics sequence and Engineering 101 will lay the foundation for engineering computing work later in the curriculum. There will be substantial coverage of CAD/CAM in the Design I course, and of software tools based on MATLAB and/or Malhemalica in the performance class. The software packages that the students use in these two early courses will be used futher in computational problems throughout the curriculum. In addition, the department is embarking on an educational soltware initiative, developing software for the engineering science courses. Much of this software is in place; it remains to put a consistent interface on what is there, add to the software base, and incorporate these modules consistently into the conrses.

Fingineering ethics

The students will have lectures on this topic in Engineering 100 . In addition, the upper-level design courses will supply some coverage, and the case studies seminar will have several cases that focus on ethics issues. 
Environmental impact and issues

The projects that the students carry out in Engineering 100 will have an emphasis on environmental impact. In addition, the performance course will include some lectures on this topic, as will the upper-level design courses. In the case studies seminar, several of the cases will focus on environmental issues.

Randomness/Uncertainty

Randomness and uncertainty are covered in the first lab course, the focus of which is instrumentation methods and data acquisition and analysis.

Teamwork and tcam leadership

Engineering 100 will have lecture material concerning team building and teamwork. Projects will be done in teams in that course, as well as the five "engineering" courses inside the aerospace department.

\subsection{Coordination with Graduate Programs}

The Task Force recommendation for a coordinated five-year Bachelor's/Master's program came, in part, from a program that Aerospace put in place in 1995. Undergraduates can, in their junior year, apply for admission to the Simultaneous Undergraduate/Graduate Study (SGUS) program. Those that are accepted receive a graduate advisor (an Aerospace faculty member), who then helps the student choose his or her technical electives to better prepare for graduate-level work. Students in the SGUS program receive, in addition to the BSE, either a MSE or a MEng at the end of (typically) five years. The MEng clegrees are practiceoriented, and serve as advanced professional degrees, providing an emphasis on engineering practice. The department offers the MSE degree and two MEng degrees:

MEng in Aerospace Engeering This degree provides greater expertise in the disciplines of aerospace engineering, along with a wider understanding of modern industrial practices. Students also receive practical experience in team organization, project development and project management, by carrying out a team project in cooperation with industry. In recent years, team projects have been carried out in cooperation with NASA, Orbital Sciences Corporation, Lockheed/Martin and Boeing Commercial Aircraft. Students are required to take courses providing breadth beyond engineering, such as business, economics, foreign languages, etc.

MEng in Space Systems This degrce, offered jointly by the Aerospace Enginecring and the Department of Atmospheric, Oceanic and Space Sciences, provides a broad interdisciplinary education in the scientific, engineering and management aspects of complex space systems. Its main goals are:

- To provide a comprehensive knowledge of space science and engineering and their inter-relationship;

- To increase depth beyond the baccalaureate level in a space-related discipline; 
- To teach the systems approach to conceiving, designing, manufacuring, managing and operating complex space systems; and

- To provide practical experience in space system design, project development, and management.

\section{Concluding Remarks}

The University of Michigan's College of Engineering and its Aerospace Engineering Department have worked over the last year and a half to design a new curriculum framework for all undergraduate students in the College, and a new curriculum specifically for Aerospace undergraduate students. The resulting curriculum:

- gives students an engineering course each semester of their freshman year;

- provides a balance of engineering science fundamentals and engineering practice/synthesis in their sophomore, junior and senior years;

- gives students the experience they need in communications, computing and team r ork throughout their four years;

- exposes students to engineering ethics, randomness and uncertainty, and environmental impact issues;

- provides enhanced flexibility for students to tailor their course work to specific career goals, including coordination with graduate programs.

The Acrospace curriculum described above has been approved by the faculty of the department, and work is currently underway on designing the new and modified courses. Students cntering in the fall semester of 1997 (i.e. the Class of 2001, a fitting date for a new Aerospace (urriculume, will go through the new curriculum.

\section{References}

[1] Strategic Planning Committee. Aerospace engineering strategic plan. Technical report, University of Michigan Department of Aerospace Engineering, 1995.

[2] ASEE project, report: Engineering education for a changing world. ASEE Prism, DGcember 1994.

[3] The vision for change: A summary report of the ABET/NSF/Industry workshops, May 1995.

[4] National Research Council Board on Engineering Education. Engineering education: Designing an adaptive system. National Academy Press, 1995.

[5] Michigan curriculum 2000 proposed changes to the undergraduate curriculum. http://www.engin.umich.edu/dept/techcomm/curric_2000. 